\title{
Estudios fílmicos: algunos retos de futuro
}

\author{
Aarón Rodríguez Serrano \\ Profesor del Departamento de Ciencias de la \\ Comunicación de la Universitat Jaume I
}

\section{Referencia de este artículo}

Rodríguez Serrano, Aarón (2020). Estudios fílmicos: algunos retos de futuro. adComunica. Revista Científica del Estrategias, Tendencias e Innovación en Comunicación, (19), 291-294. DOI: http://dx.doi.org/10.6035/2174-0992.2020.19.16.

Hace apenas un par de meses vio la luz una pequeña investigación que habíamos desarrollado afanosamente varios compañeros del departamento (Rodríguez Serrano, Palao Errando y Marzal Felici, 2019) a propósito del funcionamiento de los estudios fílmicos en las revistas indexadas (ESCI o SCOPUS) en el campo concreto de las ciencias sociales. Entre las conclusiones que allí pudieron ponerse en blanco sobre negro, destacaba que en las revistas de menor indexación nuestra disciplina constituía un $10 \%$ del total de los trabajos publicados, mientras que cuando ascendíamos en el «nivel de impacto», detectábamos una mayor renuencia de las publicaciones a dar espacio y voz a los estudios fílmicos nacionales. Junto a aquellos datos ya publicados, podemos ahora añadir: En el caso concreto de las revistas indexadas en SCIMAGO Q1 y Q2 - recordemos: los valores privilegiados por ANECA para acceder a la acreditación positiva de titular y catedrático-, la presencia de textos vinculados con nuestro campo suele ser puramente testimonial. Ciertamente, no podemos culpar a nadie de no sentir interés por nuestras investigaciones, ni tampoco a nuestros colegas de colgar los guantes cinematográficos para publicar trabajos sobre campos mucho más rentables y asequibles. Las revistas, es obvio decirlo, tienen la presión tácita de sobrevivir en un ambiente necesariamente competitivo donde la calidad, de manera ciertamente discutible, se homologa 
con el número de citas recibidas. Antes bien, sería un buen momento para hacer una profunda autocrítica dentro del campo de los estudios fílmicos para intentar saber qué estamos haciendo mal y cuál es la realidad que nos rodea. Para ello, quizá el rasero más salvaje que podemos imponernos es el de la realidad misma: podríamos estipular cómo desearíamos que funcionara la Academia, los procesos de acreditación, la revisión por pares y, en fin, todos los rudimentos de nuestra pequeña actividad cotidiana. De nada serviría: la realidad, tozuda, no está ahora mismo para admitir poesías ni buenas intenciones. Vayamos, pues, a por ella.

Ciertamente, la crisis de nuestro campo — en términos, repito, de pura practicidad - no tiene nada que ver con la calidad de nuestros trabajos. Basta con leer las monografías publicadas durante la última década en las editoriales más relevantes de nuestro campo (Shangrila Textos Aparte, Cátedra, Nau Llibres, JC, UOC, Rialp, y tantísimas otras bien situadas en el SPI) para saber que podemos estar muy orgullosos de nuestros maestros, y no en menor medida, de los que ya se perfilan como nuestros herederos. Ahora bien: es bien sabido que actualmente la monografía no tiene el mismo valor que el paper y parece responder más bien a una suerte de quijotesco capricho del investigador ya asentado, la guinda sobre el pastel curricular, el lacito que sostiene ese anecado paquete bien provisto de papers.

Es curioso que el análisis de un único film - que podría ser, en principio, un ejercicio muy compatible con el paper de 5000 o 10000 palabras - sea, sin embargo, difícilmente publicable. Y esto por una razón muy sencilla: a mayor concreción del objeto de estudio -imagínese, por ejemplo, una cinta de Nieves Conde, o una serie de planos restaurados de Segundo de Chomón-, menos posibilidad de citación por parte del resto de la comunidad académica. En un campo tan necesariamente disperso como el nuestro — en el que la actualidad inmediata, la novedad, el último aullido de la «moda cinematográfica» es atendido por la crítica cinematográfica y no por la Academia-, nuestra posición como autores es prácticamente insultante para revistas que consideran que su labor debe ser medida por la posición que ocupan en los ránkings. Parafraseando aquella famosa afirmación que ciertos ejecutivos maliciosos de los estudios RKO colgaron del cuello de Katherine Hepburn, se puede considerar que gran parte de nuestra producción es «veneno para la taquilla [del impacto]».

Por otra parte, una mirada descarnada a nuestra producción demuestra que nuestra disciplina o bien sufre una incomprensible candidez que le impide participar en el cinismo general de los tiempos, o bien ha perfeccionado vertiginosamente la capacidad de pegarse un tiro en el pie en lo que a citación se refiere. Un reciente y muy meritorio artículo desde el ámbito de la bibliometría concluía con dos datos realmente espeluznantes: el primero es la supremacía absoluta de las publicaciones de impacto en lengua inglesa (un 74,6\% del total), y el segundo es la absoluta desconexión entre nuestros trabajos: «solo 26 de las 64 revistas intercambian citas 
de artículos, sin que exista ningún núcleo central» (De la Torre Espinosa, Repiso, \& Montero Díaz, 2019).

Estos datos se confirman con una simple mirada a la manera en la que nos hemos citado en los estudios fílmicos españoles durante 2019. Un análisis realizado a vuelapluma de los dossieres publicados en nuestro campo por diferentes revistas nacionales (Icono14, Área Abierta, Documentación de Ciencias de la Información, L'Atalante, Fotocinema...) arroja una preeminencia desoladora de citas destinadas en exclusiva a la esfera anglosajona de los Film Studies y/o a los estudios franceses sobre cine. Además - y una investigación en curso ofrecerá, si todo va bien, en algún tiempo los datos concretos - podemos adelantar que el ítem más citado es la monografía de autores no hispanoparlantes, muy por encima de la producción publicada por nuestros colegas, en nuestras universidades y en nuestra lengua.

La preeminencia de fuentes de la esfera francesa y anglosajona marca inevitablemente una serie de tendencias ideológicas que apuntan, a nuestro juicio, a otro de los grandes males de nuestro campo ya apuntado por el artículo de De la Torre, Repiso y Montero: la incontestable falta de una vertebración nacional - y ya no digamos, con la esfera hispanoamericana. Por un lado, al tratarse de un campo infrafinanciado dentro de las disciplinas de comunicación -les invito a intentar localizar cuántos proyectos de I+D específicamente cinematográficos han sido concedidos en la última década-, los congresos y las actividades asociativas se han organizado casi exclusivamente con el voluntarioso empeño de algunos departamentos o de algunas Asociaciones mantenidas, generalmente, con el dinero personal de sus propios miembros. Lo mismo puede decirse de la edición de monografías, de la creación de redes de investigación o de actividades todavía más básicas como la celebración de seminarios universitarios en torno al cine - generalmente costeados por cinéfilos ajenos a la Academia, salas de cine en manos privadas o festivales que todavía tienen a bien crear secciones paralelas que cubran aquella función que no hemos sabido defender ante algunos de nuestros colegas más escépticos: nuestra voluntad de seguir siendo parte de la Universidad, de seguir participando activa y críticamente en sus dinámicas, y ya de paso, de no dejar de reivindicar nuestro estatuto como ciencia, como ciencia social y como ciencia humana.

Todavía está por escribir la estrecha conexión que existe entre Cine Español y Academia Fílmica Española. Por mucho que nos cueste verlo, somos hermanos mellizos en muchos aspectos: se nos acusa de ser inútiles, gravosos, no productivos, de no responder a las demandas del momento. Se nos mira con sospecha porque no está muy claro para qué sirven, a quién sirven. Se nos compara con nuestros hermanos mayores franceses y anglosajones, porque ellos son «los que saben hacer las cosas», y nosotros mismos, cuando nos ponemos exquisitos, confesamos que querríamos ser como Deleuze o como Bordwell - a los que citamos compulsivamente, claro-, sin dar el valor que merecen a nombres patrios como - me permitirán que me posicione- Santos Zunzunegui, José Luis Castro de Paz, 
Juan Miguel Company, Manuel Palacio, o por citar a alguien de la casa, Francisco Javier Gómez Tarín.

Sin embargo, ahí tienen la realidad de la industria: por mucho que moleste a ciertos sectores ideológicos patrios, nuestro sector audiovisual cinematográfico sigue gozando de - me perdonarán lo manido de la metáfora - una mala salud de hierro. Las nuevas generaciones de directoras y directores — consulten el catálogo de cualquier edición de los Festivales Atlántida o Márgenes, por poner apenas dos ejemplos - siguen cada año dando sentido a nuestra práctica docente e investigadora. Lo mismo puede decirse de los Estudios Fílmicos. Lo realmente misterioso de nuestro tiempo es que, contra el «Efecto Aneca» (Soriano, 2008) y contra los embistes de un modelo de conocimiento eminentemente neoliberal (Marzal Felici, Rodríguez Serrano y Gil Soldevilla, 2018), se sigan leyendo extraordinarias tesis doctorales año tras año, se sigan publicando primeros o segundos libros de gran calado teórico, se sigan inventando nuevas maneras de seguir haciendo lo que realmente queremos hacer - como colectivo, como investigadores, como universitarios-: pensar el cine y no morir de pobres en el intento.

\section{Referencias}

De la Torre-Espinosa, Mario; Repiso, Rafael; Montero Díaz, Julio (2019). Factor de Impacto y comportamiento bibliométrico de las revistas de "Film, Radio \& Television” de Web of Science. En: Revista Española de Documentación Científica, vol.42, n ${ }^{\circ} 3$. Madrid: CSIC, 1-14.

Marzal Felici, Javier; Rodríguez Serrano, Aarón; Gil Soldevilla, Samuel (2018). Introducción. Reflexiones en torno a la naturaleza y a la calidad de la investigación en comunicación. Investigar en el contexto de la expansión del pensamiento neoliberal. En: Marzal Felici, Javier; Rodríguez Serrano, Aarón; Gil Soldevilla, Samuel. Investigar en la era neoliberal. Visiones críticas sobre la investigación en comunicación en España. Barcelona, Bellaterra, Castellón y Valencia: Universitat Pompeu Fabra, Universitat Autònoma de Barcelona, Universitat Jaume I y Universitat de València, Col.lecció Aldea Global.

Rodríguez Serrano, Aarón, Palao Errando, José Antonio; Marzal Felici, Javier (2019). Los estudios fílmicos en el contexto de las ciencias sociales: un análisis de autores, objetos y metodologías en las revistas de impacto españolas (2012-2017). En: BiD: Textos Universitarios de Biblioteconomía y Documentación, vol.43. Barcelona: Universitat de Barcelona, Universitat Oberta de Catalunya.

Soriano, Jaume (2008). El “efecto Aneca.” En: I+C Investigar la Comunicación. Actas del Congreso Internacional Fundacional de la Asociación Española de Investigación de la Comunicación (AE-IC). Santiago de Compostela: Universidad de Santiago de Compostela. 